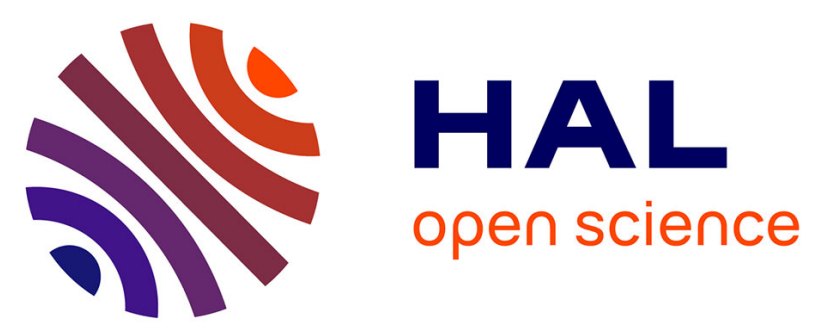

\title{
Alignment and nano-connections of isolated carbon nanotubes
}

Mathieu Sagnes, Jean-Marc Broto, Bertrand Raquet, Thierry Ondarçuhu, Christophe Laurent, Emmanuel Flahaut, Christophe Vieu, Franck Carcenac

\section{- To cite this version:}

Mathieu Sagnes, Jean-Marc Broto, Bertrand Raquet, Thierry Ondarçuhu, Christophe Laurent, et al.. Alignment and nano-connections of isolated carbon nanotubes. Microelectronic Engineering, 2003, vol. 67-68, pp. 683-689. 10.1016/S0167-9317(03)00130-8 . hal-00958084

\section{HAL Id: hal-00958084 https://hal.science/hal-00958084}

Submitted on 11 Mar 2014

HAL is a multi-disciplinary open access archive for the deposit and dissemination of scientific research documents, whether they are published or not. The documents may come from teaching and research institutions in France or abroad, or from public or private research centers.
L'archive ouverte pluridisciplinaire HAL, est destinée au dépôt et à la diffusion de documents scientifiques de niveau recherche, publiés ou non, émanant des établissements d'enseignement et de recherche français ou étrangers, des laboratoires publics ou privés. 


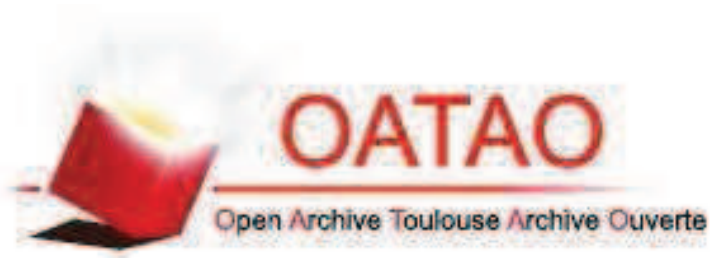

\section{Open Archive TOULOUSE Archive Ouverte (OATAO)}

OATAO is an open access repository that collects the work of Toulouse researchers and makes it freely available over the web where possible.

This is an author-deposited version published in : http://oatao.univ-toulouse.fr/ Eprints ID : 11135

To link to this article : DOI:10.1016/S0167-9317(03)00130-8

URL : http://dx.doi.org/10.1016/S0167-9317(03)00130-8

\section{To cite this version :}

Sagnes, Mathieu and Broto, Jean-Marc and Raquet, Bertrand and Ondarçuhu, Thierry and Laurent, Christophe and Flahaut, Emmanuel and Vieu, Christophe and Carcenac, Franck Alignment and nano-connections of isolated carbon nanotubes. (2003) Microelectronic Engineering, vol. 67-68 . pp. 683-689. ISSN 01679317

Any correspondance concerning this service should be sent to the repository administrator: staff-oatao@,listes-diff.inp-toulouse.fr 


\title{
Alignment and nano-connections of isolated carbon nanotubes
}

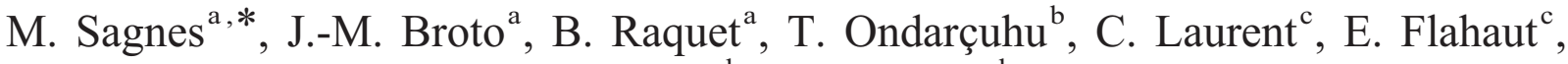 \\ C. Vieu ${ }^{\mathrm{d}}$, F. Carcenac ${ }^{\mathrm{d}}$ \\ a LPMC-LNCMP, 143 Avenue de Rangueil, BP 424531432 Toulouse, Cedex 4, France \\ ${ }^{\mathrm{b}}$ CEMES, 29 Rue Jeanne Marvig, BP 434731055 Toulouse, Cedex 4, France \\ ${ }^{\mathrm{c}}$ CIRIMAT, UMR CNRS 5085, Université Paul-Sabatier, 31062 Toulouse, Cedex 4, France \\ ${ }^{\mathrm{d}} \mathrm{LAAS}, 7$ Avenue du Colonel Roche, 31077 Toulouse, Cedex, France
}

\begin{abstract}
We report a new approach for the alignment and the electrical nano-connection of isolated carbon nanotubes (CNTs). Through a novel combination of proven technics, we have been able to align isolated carbon nanotubes and selectively contact those CNTs by high resolution electron beam lithography (HREBL). Resistance versus temperature $(R(T))$ experiments have been carried out to determine the reliability of the metal-CNTs interface and to probe the electronic conductance of the CNT.
\end{abstract}

Keywords: Carbon nanotubes; Molecular combing; Nanofabrication; Electronic transport

\section{Introduction}

Since their discovery [1], carbon nanotubes (CNTs) have been at the core of many studies because of their unique properties. With the understanding of some of the basic transport mechanisms involved in the electronic transport through CNTs, today studies become more and more oriented toward measurements on individual CNT. To achieve such an ambitious aim, we need to sharpen the tools that have been set up. Both deposition and connection of CNTs need to be reviewed and enhanced. CNTs are generally deposited on the substrate by random deposition. Once in a suspension, the CNTs are deposited by the mean of a droplet, sometimes followed by ultrasonic pulse. This deposition presents the advantage of being easy to handle, however it lacks control of the direction of the CNTs on the substrate.

To enhance this standard approach, we use the so-called 'molecular combing' [2]. It allows a rigorous orientation of the CNTs.

*Corresponding author.

E-mail address: mathieu.sagnes@insa-tlse.fr (M. Sagnes). 
The CNTs' connection to the measuring equipement is also a complex step. The patterning of the metal layer is usually done through electron beam lithography. A possible approach for the positioning of the electrodes relies on the use of alignment dots arrays to localize the CNTs and to deduce their relative coordinates with respect to the dots. This method presents a lack of flexibilty due to the predefined alignment dot arrays that, combined to a random depositon, increases the difficulty to contact an unique CNT.

Again we propose a new way to pinpoint the CNTs, and to choose the isolated CNT we want to connect through the combination of molecular combing (MC) and high-resolution electron beam lithography (HREBL).

Finally, we measure and analyze the temperature dependence of the resistance of an individual CNT in a four probe configuration. Our CNTs are synthetized by catalytic chemical vapor deposition of $\mathrm{H}_{2} / \mathrm{CH}_{4}$ at $1000{ }^{\circ} \mathrm{C}$ using a $\mathrm{Mg}_{1-x} \mathrm{Co}_{x} \mathrm{O}$ solid solution and are mainly single and double walled carbon nanotubes. [4]. After purification and extraction [4], an aqueous suspension of CNTs is obtained. We add a surfactant, sodium dodecylsulfate (SDS) in concentration of $40 \mathrm{~g} / 1$, to avoid their agglomeration.

\section{Fabrication of microelectrodes and contact pads}

We use a lowly doped silicon wafer $\left(10^{13} \mathrm{~N}\right.$ type). To avoid any transport through the substrate we need an highly insulating layer on the top of this wafer. So we proceed to the growth of a silicon oxide layer. To achieve such a layer, we use a sequence of wet $\left(\mathrm{O}_{2}\right.$ and $\left.\mathrm{H}_{2}\right)$ and dry $\left(\mathrm{O}_{2}\right.$ only) thermal growth of silicon oxide. The wet growth enables a faster growth rate at the expense of the quality of the oxide whereas the dry growth stage gives rise to a slower growth yet with a better quality. This process is $2 \mathrm{~h}$ long and the thickness of the final layer is $625 \mathrm{~nm}$ (measured by ellipsometry).

Microelectrodes and large contact pads are fabricated by optical UV lithography in contact mode. We use an AZ1529 thin film of $2.9 \mu \mathrm{m}$ thick spin-coated on the wafer as a photoresist. The transfer is done by lift-off of a $\mathrm{Ti}_{20 \mathrm{~nm}} / \mathrm{Au}_{5 \mathrm{~nm}}$ metal layer deposited in a high vacuum thermal deposition chamber.

The geometry of the microelectrodes is designed for compatibility with both subsequent MC of CNTs and fabrication of the nanoelectrodes through HREBL. As the latter is performed on a modified transmission electron microscopy (TEM), those electrodes need to converge towards a central region of $40 \times 40 \mu \mathrm{m}$ corresponding to the maximum field size of the HREBL system. Moreover the samples after UV lithography and lift-off need to be sawed in small $4 \times 4 \mathrm{~mm}$ pieces allowing their introduction in the TEM chamber. The final geometry can be seen in Fig. 1.

\section{Nanofabrication}

The first step of the nanofabrication process is the deposition of CNTs and their alignement on the predefined microelectrodes. This process is followed by the fabrication of nanoelectrodes by HREBL [3] that will connect a single CNT to the microelectrodes. 


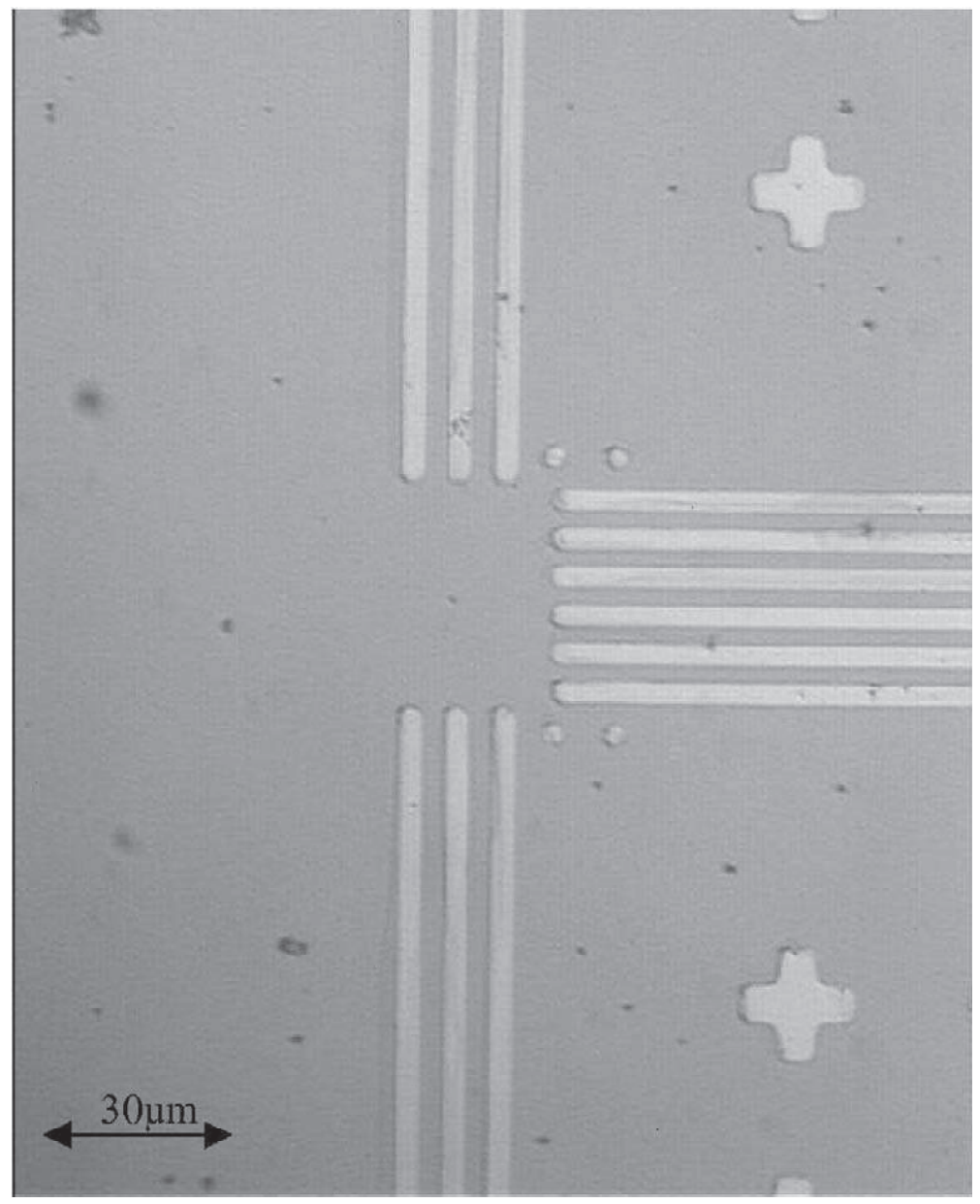

Fig. 1. Optical observation of the microelectrodes zone. The microelectrodes tips are $2 \mu \mathrm{m}$ wide.

\subsection{CNT deposition and alignment using molecular combing}

Our purpose is to optimize a process allowing the connection of only one CNT. This requires that the density of CNT left after MC be sufficient low. It is therefore absolutely necessary to control the 'affinity' of the CNTs with the surface. It has been shown previously [2] that silianisation of the $\mathrm{SiO}_{2}$ surface with perfluorodecyltrichlorosilane leads to a very good alignment of the deposited CNT and a low density of CNT on the surface. These conditions are very well adapted to our geometry as it leads to three CNTs in average in the active part of our device.

The molecular combing is achieved by diping the substrate into the CNTs suspension for 15 min to optimize the deposition efficiency. Then the substrate is pulled out of the suspension through the liquid meniscus at low speed $(200 \mu \mathrm{m} / \mathrm{s})$ and rinsed in pure water to remove the SDS layer and to clean any contaminant that may be present. 


\subsection{CNT nanoconnection using HREBL}

The strategy for connecting a single CNT is described below. First the sample is mounted in the AFM system after MC. Observation by tapping mode enables to check the presence of a few number of CNT inside the region of interest close to the macroelectrodes (Fig. 2). A CNT is selected for nanoconnection according to the following requirement: longer than $3 \mu \mathrm{m}$, diameter lower than $3 \mathrm{~nm}$ (as estimated by the height profile of an AFM scan through the CNT) and elongated shape with no strong buckling. The position of this CNT with respect to the end of the microelectrodes is determined using the AFM metrology software. The inaccuracy of the registration arises from the rough definition of the tip of the microelectrodes after UV lithography and the calibration of the AFM tool. The coordinates of the CNT are then introduced in the HREBL software for alignment of four nanoelectrodes contacting the CNT perpendicularly to its axis. Different sources of errors cumulate (alignment inaccuracy in HREBL, registration inaccuracy) and can be detrimental for succesfully achieving the four point contacts. However, as the selected CNT is long, straight and correctly

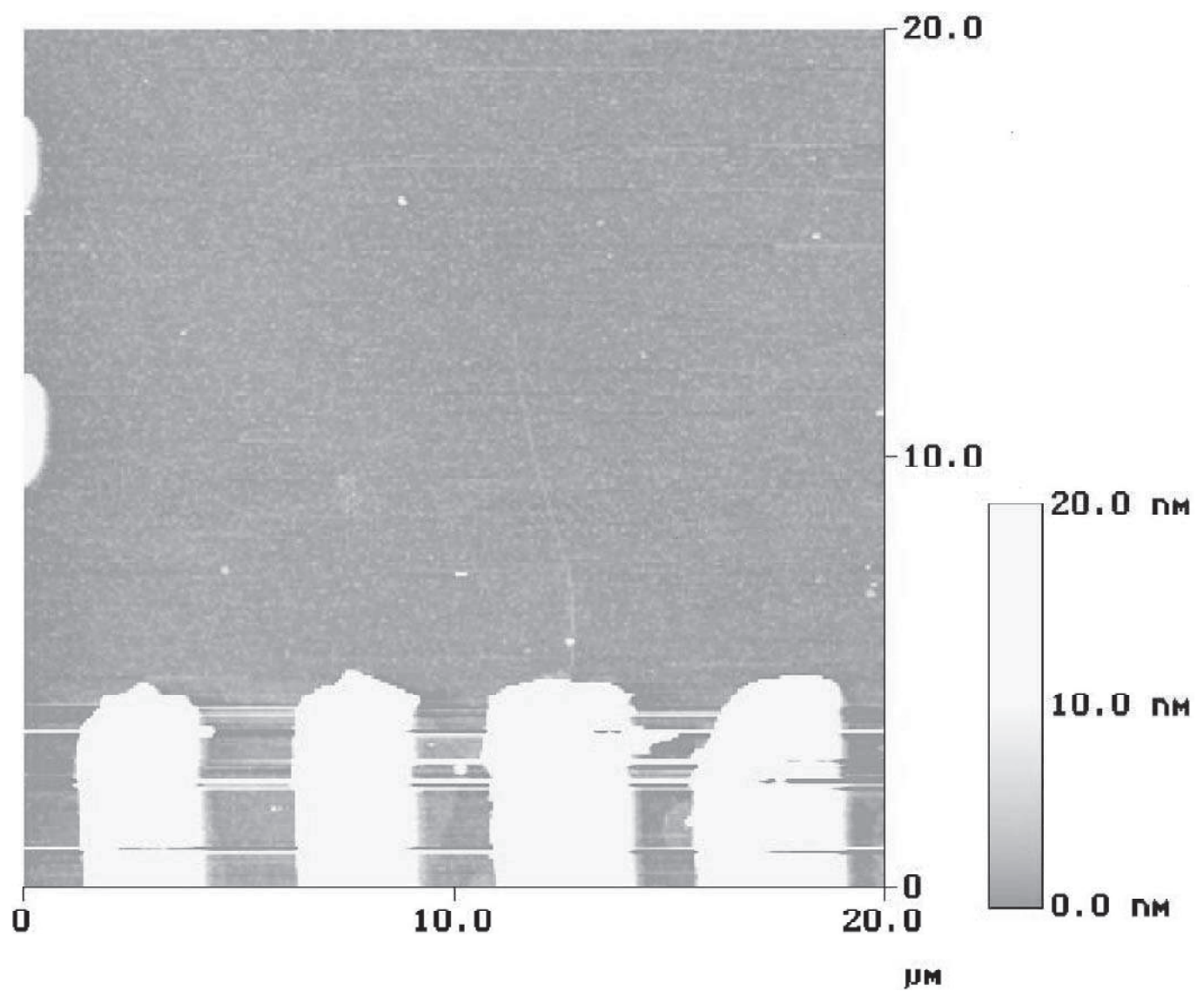

Fig. 2. AFM observation after molecular combing. An invidual CNT is clearly visible aligned with the direction of the pre-defined microelectrodes. 

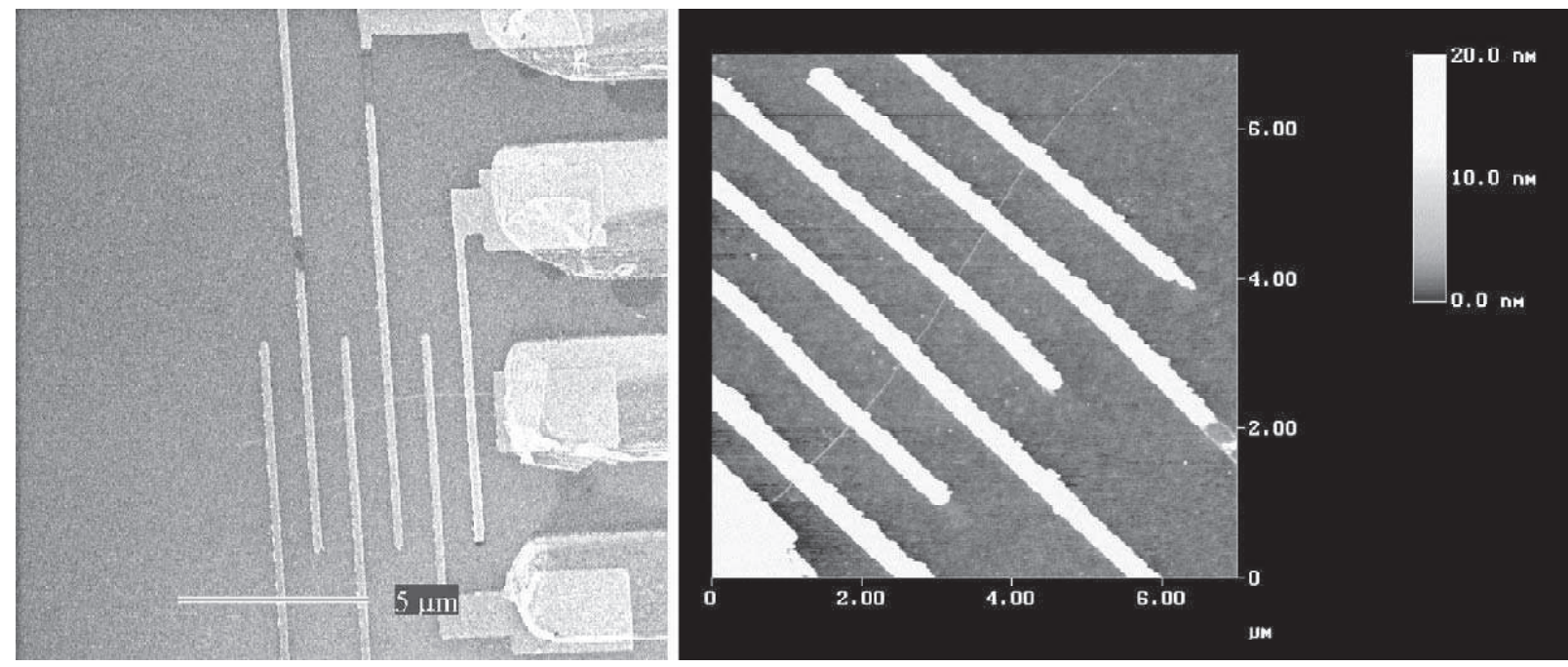

Fig. 3. On the left side, a SEM observation of a sample after nanoconnection. The nanoelectrodes $\left(\mathrm{Ti}_{20 \mathrm{~nm}} / \mathrm{Au}_{5 \mathrm{~nm}}\right) \operatorname{are} 200$ nm wide and $1 \mu \mathrm{m}$ spaced. The CNT can still be seen. On the right side, an AFM observation of the same sample.

aligned, it is quite easy to adjust the length of the electrodes for compensating possible inaccuracy (see for example Fig. 3). This may be viewed as a tedious work, but it should be kept in mind that we control the density of CNTs on the substrate. Moreover, as the direction of the CNTs is known, it is much easier to spot a CNT compared to a random deposition.

The silane layer on the top of the oxyde layer has to be removed to ensure a proper coating of the substrate by the PMMA. If that silane layer is not removed, PMMA electron beam resist cannot be spin-coated succesfully. Silane layer removal is performed through UV-ozone treatment [5]. In our experimental set-up, $10 \mathrm{~min}$ of exposure fully removed the silane layer and was thought to be harmless for the CNTs: electrical measurements on CNTs deposited directly on electrodes show very small modification after UV-ozone treatment (unpublished result). HREBL is performed at an acceleration voltage of $200 \mathrm{kV}$ and the dose for exposure of the nanoelectrodes is typically 2200 $\mu \mathrm{C} / \mathrm{cm}^{2}$. This dose is higher than the one required on a bare $\mathrm{Si}$ wafer due to the thick $\mathrm{SiO}_{2}$ insulating layer $(625 \mathrm{~nm})$, however it remains below the damaging threshold for CNTs [6].

The nanoelectrodes are fabricated by lift-off of a bilayer of $\mathrm{Ti}_{20 \mathrm{~nm}} / \mathrm{Au}_{5 \mathrm{~nm}}$ in hot trichloroethylene using ultrasonic agitation. The Ti layer provides good adhesion on the $\mathrm{SiO}_{2}$ surface, moreover it has been shown that this material is convenient for the ohmicity of the electrical contact with the CNT [7]. The capping Au layer prevents from any further oxydation of the nanoelectrodes.

A typical result of successful single CNT nanoconnection is presented on Fig. 3. The $200 \mathrm{~nm}$ wide nanoelectrodes perpendicular to the $7 \mu \mathrm{m}$ long CNT can be clearly seen. In this case, six nanoelectrodes are perfectly connecting the CNT. In Fig. 3 (left side), we can also observe the connection between the microelectrodes and the nanoelectrodes.

The yield of this procedure of nanoconnection turns out to be $100 \%$ as soon as a correct CNT, corresponding to the above mentioned requirements is observed by AFM. As our MC procedure is also very efficient (close to $100 \%$ ), we think that our whole procedure is very reliable. 


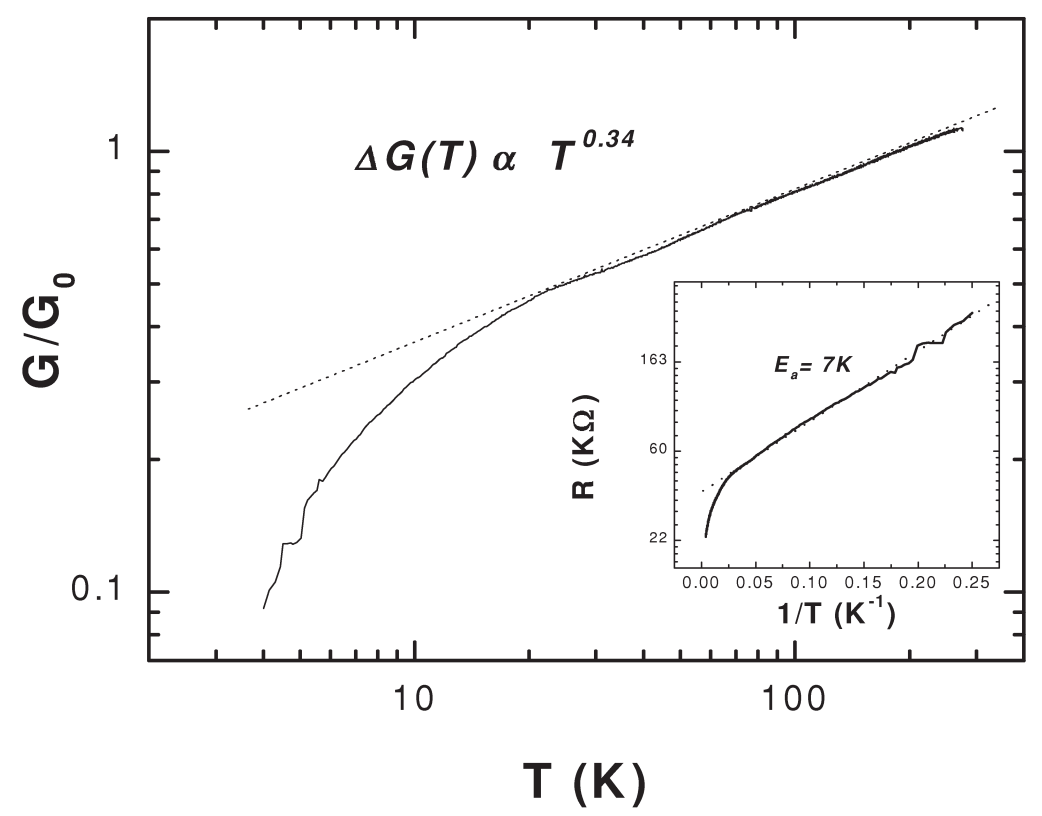

Fig. 4. Four probes conductance vs. temperature of an individual $2 \mathrm{~nm}$ diameter $\mathrm{CNT}$ measured in $\mathrm{AC}$ current $\left(f_{0}=30 \mathrm{~Hz}\right.$ and $I=0.5 \mathrm{nA}$ ). The inset illustrates a thermally activated regime below $20 \mathrm{~K}$.

\subsection{First electric characteristics}

We perform conductance vs. temperature measurements (Fig. 4) on the CNT using AC current in a two- and four-probes configuration. The CNT four-probes resistance over $1 \mu \mathrm{m}$ length is $25 \mathrm{k} \Omega$ at room temperature. The contact resistance is around $15 \mathrm{k} \Omega$. This value is slightly higher than the expected one for an ideal contact on a ballistic nanowire $\left(R_{0}=12.9 \mathrm{k} \Omega\right)$. However, this result is quite encouraging as neither thermal treatment nor electron beam exposure has been applied on the CNT-metal contacts to optimize its resistance. The contact resistance remains ohmic for currents of the order of $10 \mathrm{nA}$ at $2 \mathrm{~K}$.

The CNT conductance and its temperature dependence are not consistent with a semiconductor CNT (SC-CNT) whose energy gap should be of the order of few hundred of meV for a $2 \mathrm{~nm}$ diameter; and there is no physical reason to invoke an highly doped SC-CNT. The high temperature CNT conductance, between 20 and $300 \mathrm{~K}$, exhibits a power law temperature dependence $\left(\Delta G \propto T^{0.34}\right)$ which is consistent with a one dimensional metallic like behavior. Two cases can be envisaged: quantum corrections to the metallic conductance dominated by electron-electron interactions (1D weak localization) or electron tunneling through a Luttinger liquid [8]. The absence of low field negative magneto-resistance [9] tends to validate the Luttinger liquid behavior of the CNT. Below 20 $\mathrm{K}$, we observe a departure of the $G(T)$ law towards a thermally activated regime with a $7 \mathrm{~K}$ activation energy. Structural disorder like buckling along the tube or charge effects induced by contacts are possible explanations. Further transport experiments on the base of the nano-contacting process described above are in progress to elucidate the 1D electronic conductivity in the CNTs. 


\section{Conclusion}

We have demonstrated a new approach for depositing and contacting individual CNTs with a very high success yield. Molecular combing allows a deposition of aligned individual CNTs. The whole technological process involving UV-ozone cleaning and deposition of the nanoelectrodes by lift-off gives electrical contacts of good quality. The control of CNT alignment will enable us to realize more complex connection layouts and to contact in a single step a larger number of CNTs per sample (thanks to an easier loacalisation).

This work demonstrates that the combination of HREBL and MC is a powerful tool in the area of nanoadressing molecular objects but we have not investigated all the potentialities of the approach. This work could be further developed for achieving both alignment and positioning of an individual CNT with sub-micronic accuracy by taking advantage of the high spatial localisation of lithography technics and the ability of MC to control both the density and alignment of CNT. Our first electronic measurements on an individual $2 \mathrm{~nm}$ diameter CNT reveal a complex conductivity for which a Luttinger liquid like behavior is strongly suspected.

\section{Acknowledgements}

This work was supported in part by the CNRS ACI program NOI, Grant No. 01N22/0036.

We would like to thank the TEAM group of the LAAS Toulouse laboratory for their help in all the clean room processes. We also especially thank $\mathrm{Mr} \mathrm{T}$. Do Conto for his help on the wedge bonding and connectivity issues.

\section{References}

[1] S. Iijima, Nature (Lond.) 354 (1991) 56.

[2] S. Gerdes, T. Ondarcuhu, S. Cholet, C. Joachim, Europhys. Lett. 48 (3) (1999) 292-298.

[3] F. Carcenac, L. Malaquin, C. Vieu, Microelec. Eng. 61-62 (2002) 657-663.

[4] E. Flahaut, A. Peigney, Ch. Laurent, A. Rousset, J. Mater. Chem. 10 (2000) 249.

[5] J.R. Vig, J. Vac. Sci. Technol. A 3 (1985) 1027.

[6] A. Bachtold, M. Henry, C. Terrier, C. Schönenberger, J.-P. Salvetat, J.-M. Bonard, L. Forro, Appl. Phys. Lett. 73 (2) (1998) 274-276.

[7] Y. Zhang, N.W. Franklin, R.J. Chen, H. Dai, Chem. Phys. Lett. 331 (1) (2000) 35-41.

[8] J. Nygard, D.H. Cobden, M. Bockrath, P.L. McEuen, P.E. Lindelof, Appl. Phys. A 69 (1999) 297.

[9] M. Sagnes et al., in press. 